Article

\title{
Study on the Stabilization Mechanisms of Clayey Slope Surfaces Treated by Spraying with a New Soil Additive
}

\author{
Cuiying Zhou ${ }^{1,2,3}$, Shanshan Zhao ${ }^{1,2,3}$, Wei Huang ${ }^{1,2,3}$, Dexian Li $^{1,2,3}$ and Zhen Liu $1,2,3, *$ (D) \\ 1 School of Civil Engineering, Sun Yat-sen University, No.135 XinGangXiLu, Guangzhou 510275, China; \\ zhoucy@mail.sysu.edu.cn (C.Z.); zhaoshsh3@mail2.sysu.edu.cn (S.Z.); \\ huangw226@mail2.sysu.edu.cn (W.H.); lidx9@mail2.sysu.edu.cn (D.L.) \\ 2 Guangdong Engineering Research Centre for Major Infrastructure Safety, School of Civil Engineering, \\ Sun Yat-sen University, Guangzhou 510275, China \\ 3 Research Center for Geotechnical Engineering and Information Technology, Sun Yat-sen University, \\ No.135 XinGangXiLu, Guangzhou 510275, China \\ * Correspondence: liuzh8@mail.sysu.edu.cn
}

Received: 17 February 2019; Accepted: 22 March 2019; Published: 25 March 2019

\begin{abstract}
The topsoil of a clayey slope is easily washed off by rain due to its loose structure. To protect the slope surface, in recent years, several types of non-traditional soil additives have been used by means of mixing with soil. In this work, a new organic polymer soil stabilizer, named aqua-dispersing-nano-binder (ADNB), was sprayed on the soil surface to stabilize the topsoil of a clayey slope. To understand the interaction between the polymer and soil particles during the infiltration process as well as the stabilization mechanism, infiltration tests, water stability tests and scanning electron microscopy (SEM) analyses were performed with different polymer contents. The infiltration tests showed that the infiltration rate of the polymer stabilizer in the soil was slower than that of water due to its characteristics of easy adhesion to soil particles, poor fluidity and large molecular volume. The maximum effective infiltration depth was achieved in the specimen treated with $2 \% \mathrm{ADNB}$, and the minimum was achieved in the specimen treated with 5\% ADNB. The water stability of the soil increased with the content of the soil stabilizer in the soil aggregates with diameters of either 5-10 $\mathrm{mm}$ or 10-20 mm. The SEM analysis showed that the quantity of polymer decreased with infiltration depth; a polymer membrane was formed on the surface of the topsoil and chains were formed inside. The amelioration of the soil water stability may have been due to the bonding between soil particles and polymers generated after evaporation of water in the emulsion. The polymer stabilizer could be applied to improve the erosion resistance of the slope topsoil and reduce soil loss.
\end{abstract}

Keywords: new soil additives; effective infiltration depth; water stability; silty clay; stabilization mechanisms

\section{Introduction}

Clayey slopes are extensively distributed in southern China. The topsoil of a clayey slope is easily washed off by rain due to its loose structure and weak water stability [1]. The loss of topsoil of clayey slopes causes great damage to the environment. With the loss of soil, the clayey slope becomes unstable due to the reduction in soil strength and the lack of reinforcement of plant roots. Traditional methods to protect the slope surface include physical methods and inorganic chemical stabilization methods. Physical methods, such as geotextiles, support the external forces without modifying the soil properties [2-5]. Although inorganic chemical stabilization methods can greatly improve the 
engineering properties of soils and have been widely applied [6-13], the inorganic materials in soils will inhibit plant growth, which is unfavorable to the ecological development of slopes [14,15].

In recent decades, non-traditional chemical additives such as polymers, enzymes, ionic substances, lignosulfonates, salts and petroleum resins have been studied [16-27]. Non-traditional soil stabilization additives consist of a variety of chemical agents that are diverse in their composition and in the ways they interact with the soil. Many researchers have studied stabilization additives to improve the physical and engineering properties of soil to meet the requirements of different engineering practices $[28,29]$. Calcium carbide residue (CCR), a by-product of the acetylene production process, was investigated for its ability to improve the engineering properties of clays [30]. A new calcium-based powder additive named SH-85 was used for the stabilization of a tropical residual laterite soil [31]. Xanthan gum was proposed as an environmentally friendly stabilizer that could improve the engineering properties of both low- and high-swelling clays [32]. SS299 was a liquid polymer stabilizer used as a compaction aid or a stabilizer for soil improvement that could increase the unconfined compressive strength of kaolin [20]. Biosolids have been reported to modify the aggregate stability [33]. Polyacrylamide could improve the water stability of clay aggregates [34,35]. However, these studies were all based on the method of mixing stabilizers and soils.

An effective way to protect the topsoil of a slope is to spray the stabilization additive onto the surface of the slope without any disturbance. In this case, the stabilization additive should be able to dissolve or disperse in water, unlike organic solvents, which are harmful to the environment. Therefore, it was important to conduct a survey to fully understand the effective infiltration depths of stabilization additives. A new soil additive named aqua-dispersing-nano-binder (ADNB) was applied in this work. Efforts were made to study the mechanism of the water stability of silty soil that had been modified by the polymer emulsion. Various tests were performed with different polymer contents including infiltration tests to obtain the effective depth that the polymer could reach, water stability tests to estimate the water stability of the modified silty clay and scanning electron microscopy (SEM) to analyse the possible mechanism that contributed to the stabilization process. Furthermore, the infiltration mode of the polymer emulsion was identified, and the possible stabilization mechanism was discussed based on the infiltration process and SEM results.

\section{Materials and Testing Programs}

\subsection{Materials}

\subsubsection{Silty Clay}

The silty clay examined in this study was obtained from Guangzhou city of Guangdong Province, China. The basic properties were determined according to the methods in GB/T 50123-1999, a standard of soil testing methods in China. Table 1 summarizes the physical properties of the soil.

Table 1. Characteristics of the natural soil.

\begin{tabular}{cc}
\hline Physical Properties & Values \\
\hline Specific gravity & 2.70 \\
Liquid limit $(\%)$ & 25.76 \\
Plastic limit $(\%)$ & 14.10 \\
Plasticity index $(\%)$ & 11.66 \\
BS classification & MLS \\
Maximum dry density $\left(\mathrm{g} / \mathrm{cm}^{3}\right)$ & 1.864 \\
Optimum moisture content $(\%)$ & 15.10 \\
\hline
\end{tabular}

\subsubsection{Organic Polymer}

The organic polymer emulsion named ADNB applied in this work as a soil additive was a white viscous liquid, as shown in Figure 1a. As a new type of soil additive, ADNB could be dispersed in 
water as nanoscale particles, and its suitable anti-hydrolysis properties resulted in ADNB always retaining its polymer chains, even when dispersed in water. Upon reducing the ADNB solution via water evaporation, ADNB would turn into its membrane form, which had a suitable elasticity (Figure 1b). When the ADNB membrane was immersed in water, it became soft but remained intact and permeable. The final degradation products of $\mathrm{ADNB}$ were $\mathrm{CO}_{2}$ and $\mathrm{H}_{2} \mathrm{O}$, which are friendly to the environment [36,37]. The physical properties of ADNB are provided in Table 2.

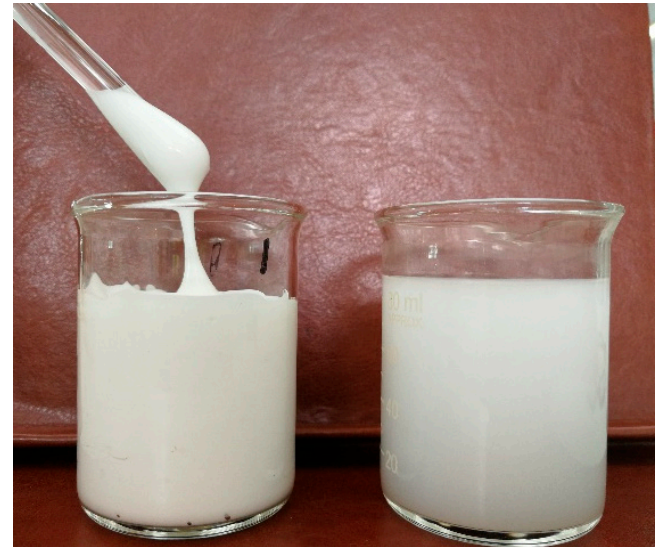

(a)

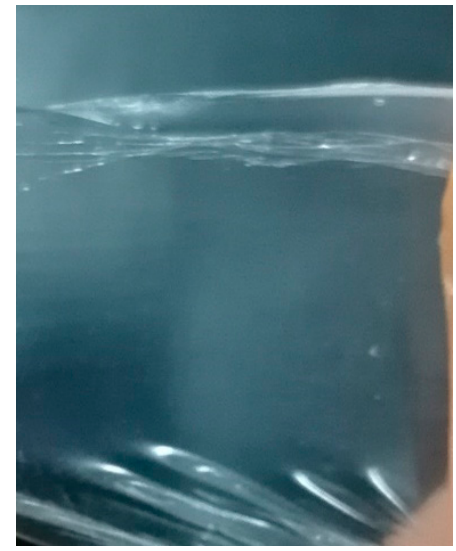

(b)

Figure 1. Different states of the aqua-dispersing-nano-binder (ADNB) polymer emulsion: (a) initial state (left), dispersed in water (right); (b) after water evaporation, an elastic film is generated.

Table 2. Characteristics of the organic polymer emulsion.

\begin{tabular}{cc}
\hline Physical Properties & Values \\
\hline Specific gravity $\left(\mathrm{g} / \mathrm{cm}^{3}\right)$ & 1.01 \\
$\mathrm{pH}$ & $6-7$ \\
Solid content $(\%)$ & 41 \\
Water soluble & No \\
\hline
\end{tabular}

\subsection{Sample Preparation}

\subsubsection{Test of the Effective Infiltration Depth}

To ensure the uniformity of the specimens, the silty clay was oven dried and sieved through a $2 \mathrm{~mm}$ mesh. Six samples were prepared at the same time. For each sample, $15 \mathrm{~g}$ of soil was first placed in a tube, which was $15 \mathrm{~mm}$ in diameter and $80 \mathrm{~mm}$ in height and closed off at one end by a permeable film. Then, the tubes were vibrated until all the soil samples had a height of $50 \mathrm{~mm}$.

To ensure that the soil samples could be completely infiltrated, a certain quantity of water was measured and filled in a container to reach a moisture content of $20 \%$, which was between the plastic and liquid limits of soil. Polymer emulsions with weights of $0.5 \%, 1.0 \%, 2.0 \%, 3.0 \%$ and $5.0 \%$ of that of the dry soil were dispersed in prepared water to obtain polymer solutions with different concentrations. Finally, the five solutions, and pure water as a reference, were sprayed slowly onto the soil surface in the six prepared test tubes. The evolution of the infiltration depths of the solutions in the soil was recorded.

According to engineering practices, the part of the soil in which the polymer emulsion achieved thorough infiltration should have a high degree of water stability. Hence, the effective infiltration depth of the polymer emulsion could be determined by immersing the soil samples in water and measuring the remaining height, $\mathrm{H}$, of the soil samples after immersion. To perform the experiments, the test tubes were fixed vertically in a dry container without contacting the bottom. Then, the container was slowly filled with water from the bottom until the soil was completely under water (Figure 2). The time 
of immersion until collapse occurred was measured as $10 \mathrm{~min}$. Three specimens were tested for each experiment, and their average was calculated as the result of the experiment.

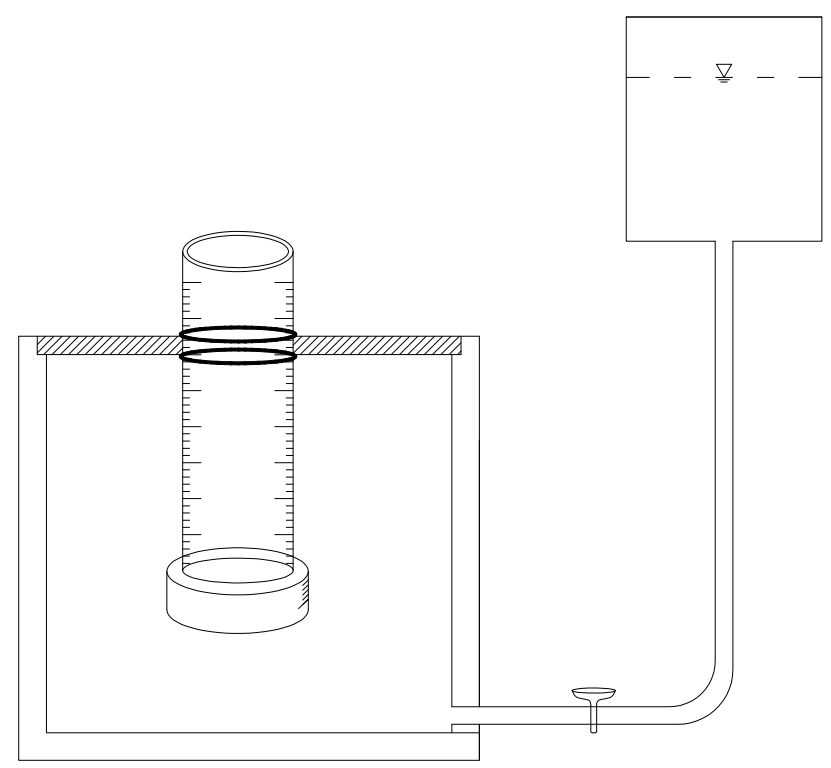

Figure 2. Apparatus of the effective infiltration depth test.

\subsubsection{Test of the Water Stability}

The water stability of aggregates has a significant impact on the erosion resistance of the slope topsoil. Aggregates with good water stability will not be washed off easily, thereby reducing the loss of soils and nutrients on the slope. Combined with vegetation growth promoted by the good structure between soil aggregates, the erosion resistance of the slope topsoil can be further improved under the joint action of self-stability of aggregates and reinforcement of soils by vegetation. First, the soils were oven dried and sieved through a $2 \mathrm{~mm}$ mesh to ensure homogeneity of the soil. The dried soils were then mixed well with water to the optimum moisture content (OMC), which was determined by a standard Proctor compaction test (GB/T 50123-1999). Thereafter, the humid soils were placed in sieves with mesh sizes of approximately 20,10 and $5 \mathrm{~mm}$. The sieves were shaken to divide the aggregates into two groups: the aggregates that remained on the $10 \mathrm{~mm}$ (the diameter of the aggregates was between 10 and $20 \mathrm{~mm}$, which was noted as an average diameter of $15 \mathrm{~mm}$ ) and $5 \mathrm{~mm}$ (the diameter of the aggregates was between 5 and $10 \mathrm{~mm}$, which was noted as an average diameter of $7.5 \mathrm{~mm}$ ) sieves.

The preparation of the polymer solution was the same as that used to test the effective infiltration depth. The different polymer solutions were then sprayed onto the surfaces of the different groups of aggregates and kept at a constant temperature of $25^{\circ} \mathrm{C}$ for three days. The results are collected in Table 3, where the notation of the test group included the average diameter of the aggregates and the applied solution (UNT indicates water without ADNB).

The water stability test required immersing the aggregates in static water. Fifty aggregates were randomly placed on a sieve covered by filter paper. To avoid the sudden disintegration of aggregates, immersion was begun with capillarity; water was added to a level at which the filter paper was just immersed. Thereafter, water was slowly added until all aggregates were submerged. The immersion time was set as $10 \mathrm{~min}$, and the cumulative number of collapsed aggregates was recorded every minute for $10 \mathrm{~min}$. The water stability index $\mathrm{K}$ was calculated with the following formula:

$$
K=\frac{\left(a_{1} \times 5+a_{2} \times 15+a_{3} \times 25+\cdots+a_{10} \times 95+a_{\infty} \times 100\right)}{50}
$$

where $a_{1}, a_{2}, a_{3} \ldots a_{10}$ represent the number of collapses at an immersion time of $1 \mathrm{~min}, 2 \mathrm{~min}, 3 \mathrm{~min}$, ... $10 \mathrm{~min}$ and $a_{\infty}$ is the number of aggregates that remained intact after $10 \mathrm{~min}$. The coefficients of 5 , 
15,25 and 100 represented the water stability of the soil aggregates during each minute. That means that if an aggregate collapsed within $1 \mathrm{~min}$, its coefficient was defined as 5 , which was calculated by $(0+10) / 2$. If an aggregate collapsed between 1 and $2 \mathrm{~min}$, its coefficient was defined as 15 , which was calculated by $(10+20) / 2$. If the aggregate never collapsed during the immersion time of $10 \mathrm{~min}$, its coefficient was defined as 100 . The $K$-value had a range of 5 to 100 . A higher $K$-value represented higher water stability of the soil aggregate.

\section{Results and Discussion}

\subsection{The Effective Infiltration Depth}

Figure 3 shows the evolution of the infiltration depth of the polymer solution or water. Water infiltrated the soil faster than the polymer solution. Approximately three hours were required for water to completely infiltrate the entire sample $(50 \mathrm{~mm})$. Within the same period, the $0.5 \%$ ADNB solution infiltrated $30 \mathrm{~mm}$, which was $3 / 5$ of the whole length.

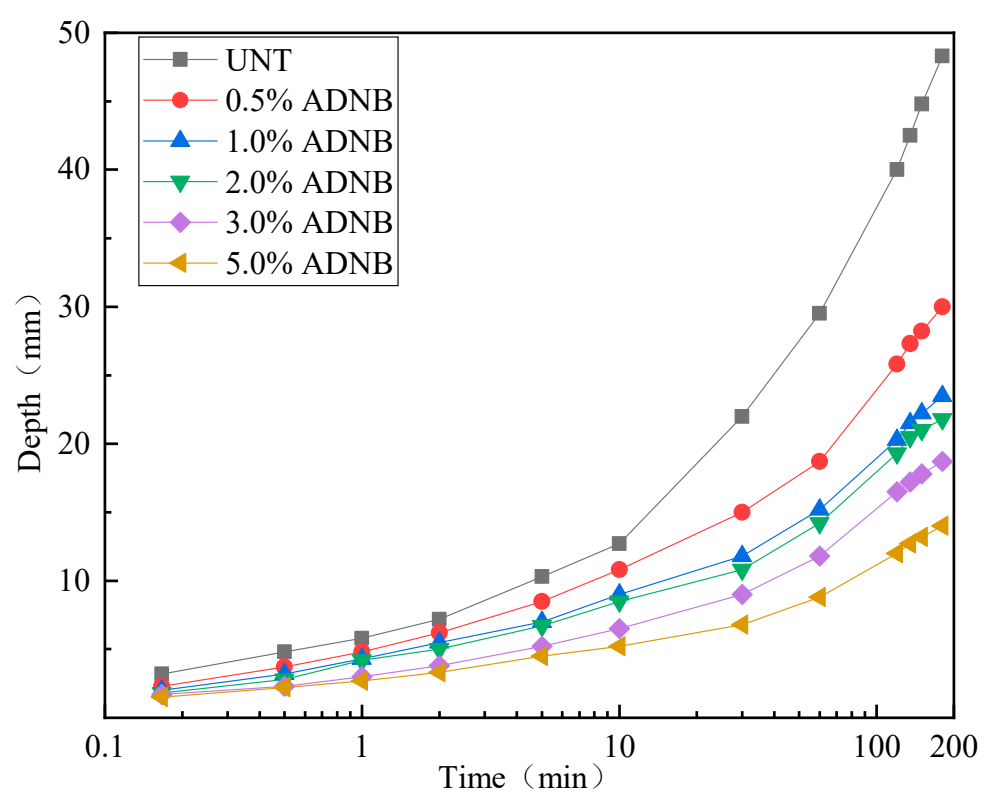

Figure 3. Evolution of the infiltration depth of the polymer solution or water.

However, the observed infiltration depth of the solution may not be exactly the effective infiltration depth of the polymer, which may be characterized by the remaining length of the soil samples after 10 min of immersion (shown in Figure 4). The soil sample treated with water completely disintegrated within $1 \mathrm{~min}$. The sample treated with $2 \%$ ADNB had a maximum effective infiltration depth of $5.5 \mathrm{~mm}$ (Figure 5). 


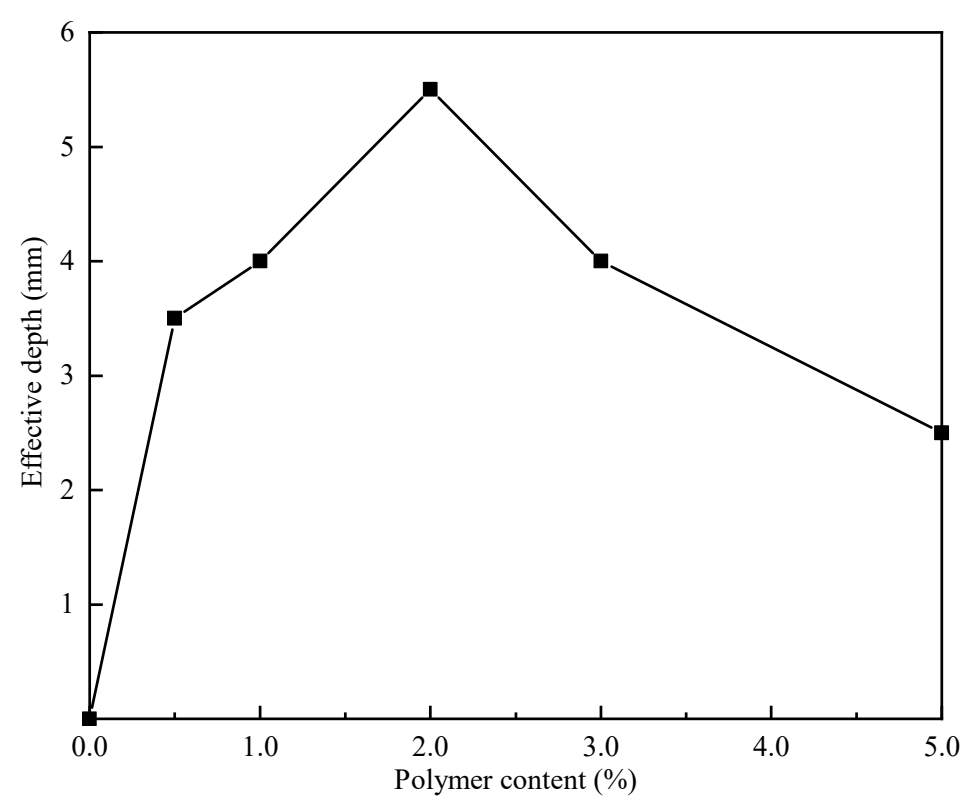

Figure 4. The effective infiltration depth of ADNB.

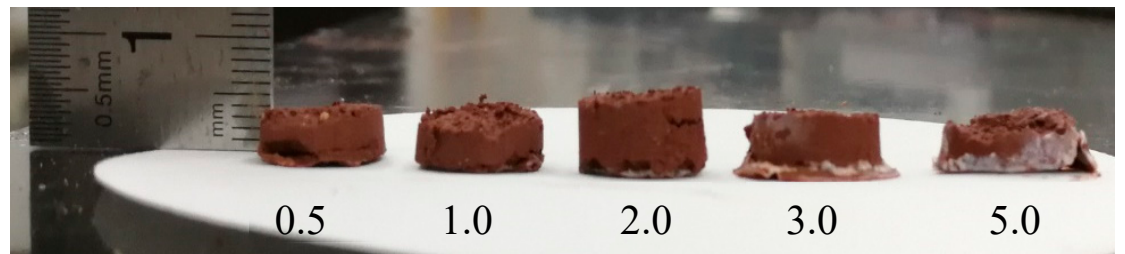

Figure 5. Residuals of the different soil samples after immersion.

When the concentration of the polymer emulsion was lower than $2 \%$ ADNB, the water-stable length of the soil sample increased with the concentration of the polymer emulsion. However, a polymer emulsion concentration higher than $2 \%$ resulted in an adverse effect: the effective water-stable length of the soil sample treated with 5\% ADNB was only $2.5 \mathrm{~mm}$, which was $45 \%$ of the maximum. Since the polymer emulsion was viscous and easily adhered to the soil particles, during the infiltration and adherence of the polymer emulsion to the soil, small particles agglomerated and the number of pores in the soil decreased. The polymer solution with a high concentration easily reached the infiltration limit where the pores of the surface soil layer were completely filled with polymer solution and an impermeable layer had formed through which polymers could not pass. Thus, the additional polymer emulsion was prevented from infiltrating and accumulated to a certain thickness on the surface (Figure 6). The higher the concentration of the polymer solution was, the quicker the impermeable layer formed, and the less the polymer solution could infiltrate the soil; as a result, a decrease in the effective water-stable depth was observed.

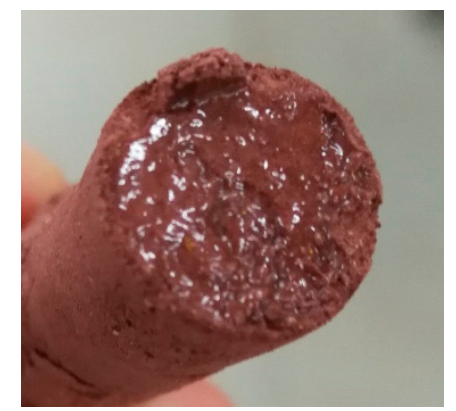

Figure 6. Accumulation of the polymer emulsion on the surface. 


\subsection{Water Stability of the Aggregates}

The cumulative number of disintegrated aggregates was recorded every minute for $10 \mathrm{~min}$ and the stability percent values, noted as $K$, are shown in Table 3. A significant increase in the water stability of the aggregates was observed due to the ADNB treatment. For example, in the test group of $7.5 \mathrm{~mm}$ aggregates, $K$ increased to over $90 \%$ when treated with $3 \%$ ADNB, which was approximately 17 times higher than that of the untreated aggregates. Similarly, $K$ increased to $98.5 \%$ when treated with $5 \% \mathrm{ADNB}$, which was approximately 19 times higher than that of the untreated aggregates. Furthermore, less soil was washed off and/or fewer aggregate structures were destroyed by water due to the significant increase in the water stability of the aggregates. As a result, the erosion resistance of slope topsoil was improved.

Table 3. Static water stability of the different aggregates.

\begin{tabular}{cccccccccccc}
\hline \multirow{2}{*}{ Test Group } & \multicolumn{10}{c}{ Immersion Time (min) } & \multirow{2}{*}{ Stability $\boldsymbol{K}(\mathbf{\%})$} \\
\cline { 2 - 10 } & $\mathbf{1}$ & $\mathbf{2}$ & $\mathbf{3}$ & $\mathbf{4}$ & $\mathbf{5}$ & $\mathbf{6}$ & $\mathbf{7}$ & $\mathbf{8}$ & $\mathbf{9}$ & $\mathbf{1 0}$ & \\
\hline 7.5-UNT & 50 & 50 & 50 & 50 & 50 & 50 & 50 & 50 & 50 & 50 & 5 \\
15-UNT & 50 & 50 & 50 & 50 & 50 & 50 & 50 & 50 & 50 & 50 & 5 \\
7.5-ADNB 0.5\% & 8 & 35 & 50 & 50 & 50 & 50 & 50 & 50 & 50 & 50 & 16.4 \\
15-ADNB 0.5\% & 10 & 20 & 21 & 34 & 35 & 45 & 50 & 50 & 50 & 50 & 32 \\
7.5-ADNB 1.0\% & 0 & 5 & 13 & 20 & 30 & 38 & 40 & 45 & 48 & 50 & 47.2 \\
15-ADNB 1.0\% & 0 & 0 & 0 & 5 & 11 & 25 & 30 & 41 & 45 & 45 & 64.1 \\
7.5-ADNB 2.0\% & 5 & 5 & 8 & 13 & 16 & 21 & 27 & 30 & 32 & 35 & 65.1 \\
15-ADNB 2.0\% & 0 & 0 & 0 & 0 & 0 & 0 & 0 & 5 & 5 & 10 & 97 \\
7.5-ADNB 3.0\% & 0 & 0 & 0 & 3 & 3 & 5 & 5 & 8 & 10 & 13 & 91.9 \\
15-ADNB 3.0\% & 0 & 0 & 0 & 0 & 0 & 0 & 0 & 0 & 0 & 0 & 100 \\
7.5-ADNB 5.0\% & 0 & 0 & 0 & 0 & 0 & 0 & 0 & 3 & 3 & 3 & 98.5 \\
15-ADNB 5.0\% & 0 & 0 & 0 & 0 & 0 & 0 & 0 & 0 & 0 & 0 & 100 \\
\hline
\end{tabular}

It was also observed that even when treated with the same concentration of polymer solution, the $K$ values of the $15 \mathrm{~mm}$ aggregates were higher than those of the $7.5 \mathrm{~mm}$ aggregates. For example, when treated with $2 \% \mathrm{ADNB}$, the $K$ value of of the $15 \mathrm{~mm}$ aggregate was $97 \%$, which was 1.5 times that of the $7.5 \mathrm{~mm}$ aggregate. Additionally, when treated with 3.0\% ADNB and 5.0\% ADNB, the $K$ values of the samples increased to $100 \%$, which indicated that the aggregates maintained their integrity during the immersion period of $10 \mathrm{~min}$. This result could be explained by the fact that the aggregates with larger diameters had smaller specific surface areas, on which there were larger amounts of effective polymer emulsions than on the aggregates with smaller diameters.

Figure 7 shows the comparison of the $K$ values of the aggregates with average diameters of $7.5 \mathrm{~mm}$ and $15 \mathrm{~mm}$. Almost no difference in the $K$ value was observed when the aggregates were treated with a high-concentration polymer solution (higher than $2 \%$ ADNB). This result may have been due to the amount of polymer that exceeded the amount required for bonding in the samples. Based on the analysis results obtained from the effective infiltration test, the polymer solution with a concentration of $3 \% / 5 \%$ ADNB could rapidly fill the pores of the surface soil layer due to its high proportion of polymer material, which led to the halting of infiltration of the additional polymer emulsion and the formation of a thick film on the surface. The film could then prevent the aggregates from disintegration during the 10 min immersion (Figure 8). 


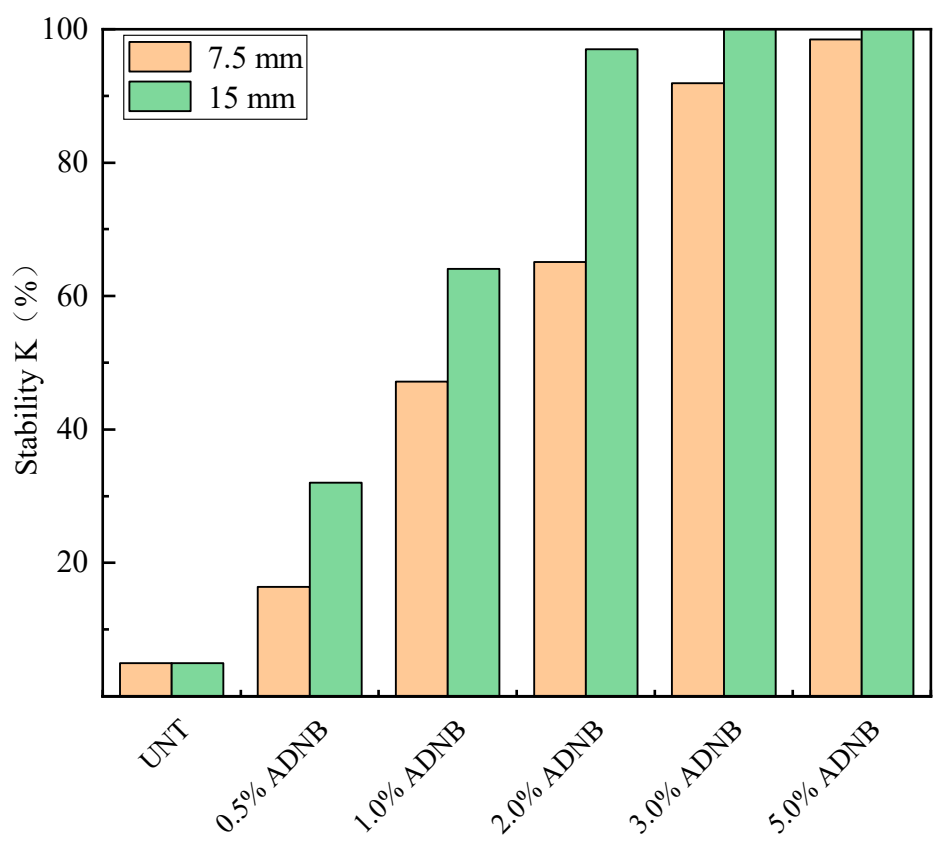

Figure 7. $K$ values of the different aggregates treated with ADNB.
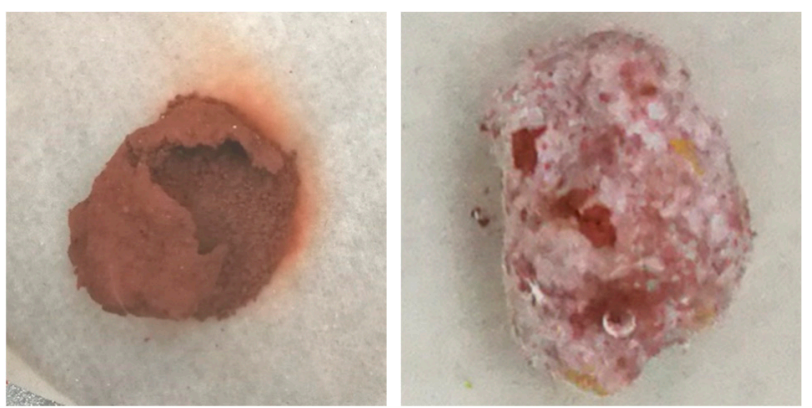

Figure 8. Aggregates treated with $0.5 \%$ ADNB (left) and 5.0\% ADNB (right).

\section{Infiltration Mode and Stabilization Mechanism}

The results of the tests performed in this work showed that the ADNB polymer was an effective soil stabilization material which infiltrated the soil and formed a protective shell of a certain thickness on the soil surface.

The process of infiltration and the stabilization mechanism of the polymer emulsion are shown in Figure 9. The untreated aggregates were composed of numerous particles and contained pores of varying sizes benefiting the circulation of air and water (Figure 9a). In contrast to the penetration behavior of water in soil, viscous polymer emulsions enclosed soil particles through bonding during infiltration. The thickness of the polymer emulsion on the outer aggregate particles was more important than that of emulsion on the inner particles (Figure 9b). 


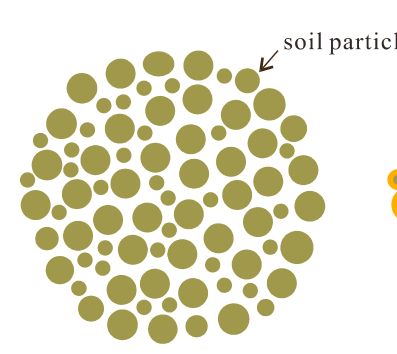

(a)

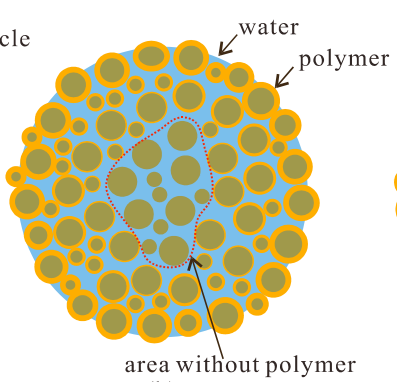

(b)

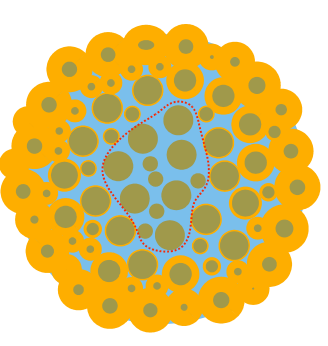

( c)

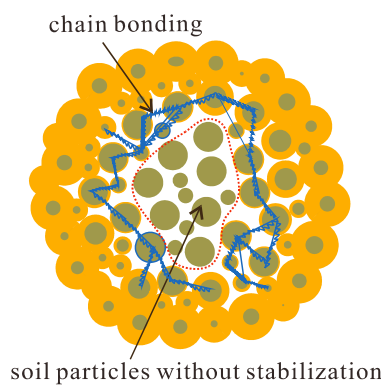

(d)

Figure 9. Illustration of the infiltration and stabilization mechanism of the polymer emulsion on the surface of the soil aggregates: (a) untreated aggregate; (b) polymer emulsion infiltrated the soil; (c) polymers gathered on the surface; (d) soil-polymer matrix formed after water evaporating.

The polymer emulsion first adhered to the external soil particles, which reduced the number of pores in the surface soil layer. On the other hand, water, which has a low viscosity, first reached the inner aggregates and filled the pores, which prevented the continuous infiltration of the polymer emulsion. Therefore, the quantity of infiltrated polymer in the interior of the aggregate was greatly decreased. As a result, an increasing amount of polymer emulsion gathered on the surface of the aggregate (Figure 9c). Inside the aggregate, the water would prevent the polymer from adhering to the inner soil particles. When the aggregate had been completely infiltrated by water, the polymer emulsion could not be driven by water to continue the infiltration due to the lack of water flow potential. Without ADNB, the internal soil particles could not be stabilized (Figure 9b). When the water in the solution evaporated, polymer coated the soil particles and formed a soil-polymer matrix that acted as a stabilized shell of a certain thickness (Figure 9d).

SEM images of the aggregates showed two ways for ADNB to stabilize particles: a membrane structure and chain bonding. The surface of the aggregate treated with $2 \%$ ADNB is shown in Figure 10a, which indicated that a smooth surface morphology had formed resulting from polymer molecules filling the pores and the bonding between particles. Figure 10b shows the surface of the aggregate treated with $5 \% \mathrm{ADNB}$, where a membrane could be observed that had completely adhered to the particles and filled the pores.

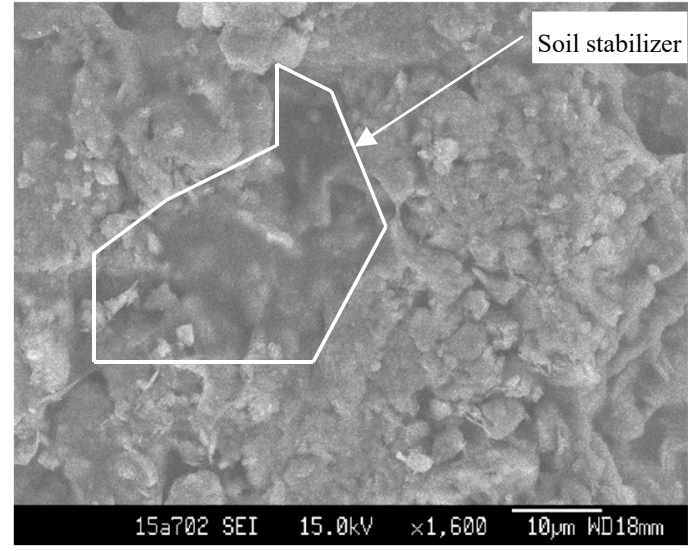

(a)

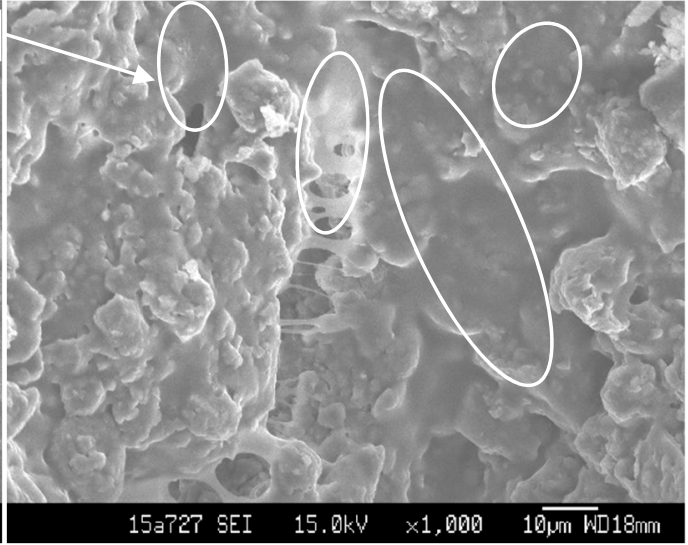

(b)

Figure 10. SEM images of the aggregate surfaces: (a) treated with $2 \%$ ADNB; (b) treated with $5 \%$ ADNB.

SEM images of the interior of an aggregate are shown in Figure 11. Only a small amount of polymer emulsion had reached this zone, which was insufficient to form an integrated membrane structure and instead just formed chains. The chain bonding was weak compared with the membrane structure. Because of the excellent elasticity of ADNB, the integrated membranes coated on particles 
and/or filled in soil pores played a major role in protecting the aggregates from collapsing when immersed in water.

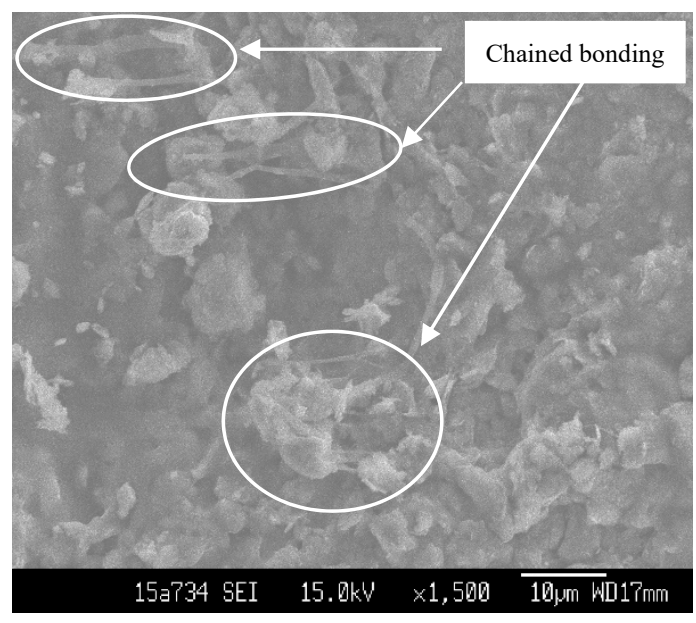

Figure 11. SEM image of the interior of the aggregates.

The particle-polymer matrix significantly improved the water stability. When a modified aggregate was immersed in water, the water molecules could not immediately penetrate into the interior because of the stabilized shell. The water first completely infiltrated the membrane that coated the soil particles and/or filled the pores and then further entered the interior of the aggregate. During this process, the aggregate remained stable in the water. Thereafter, the aggregates would become saturated with water, and swelling of the soil particles would then generate an inner expansion pressure (Figure 12a). Due to its elasticity, the membrane remained intact in the water until it was disturbed by forces. The membrane ruptured when the inner expansion pressure exceeded the strength of the membrane structure. The membrane broke at the location with a stress concentration. With the outflow of internal particles, the outer protective shell gradually tore along the rupture until it reached a stable state. The inner particles flowed out of the aggregates in the form of discrete particles as well as small aggregates due to the weak chain bonding (Figure 12b), while the outer protective shell disintegrated.

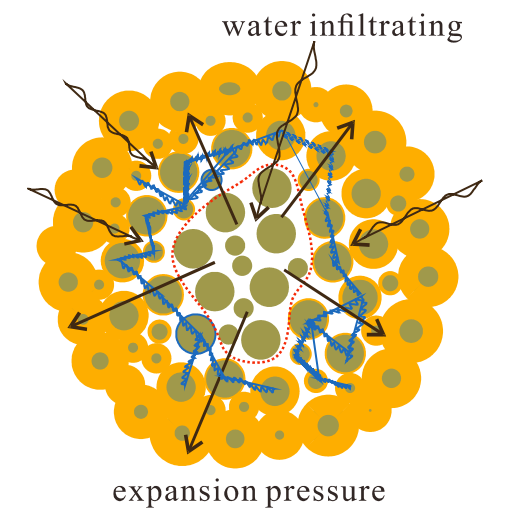

(a)

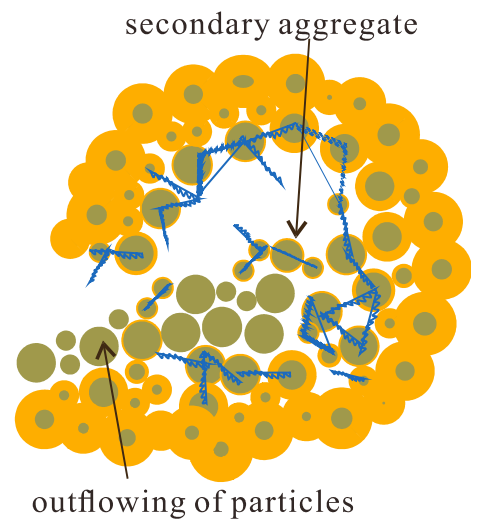

(b)

Figure 12. Illustration of the mechanism of water stability of the aggregates: (a) inner expansion pressure generated; (b) stabilized shell ruptured by the inner expansion pressure.

\section{Conclusions}

The ADNB polymer was a suitable choice as a soil stabilizer due to its special characteristics, such as uniform nanoscale particles when dispersed in water, which permitted the polymer to penetrate 
into the very small pores of soil, and suitable cohesive properties, which permitted it to play a better role in bonding soil particles together. To understand the penetration process of the soil stabilizer and the stabilization mechanism, laboratory trials of infiltration tests and water stability tests were performed. The mode of infiltration of ADNB in the soil as well as the stabilization of soil were proposed. The mechanism of water stability was analysed based on SEM images. The main conclusions can be summarized as follows:

(a) The ADNB polymer emulsion had the characteristics of easy adhesion to soil particles, poor fluidity and large molecular volume. The effective infiltration depth of soil reached a maximum for samples treated with $2 \%$ ADNB and decreased when the concentration of ADNB increased.

(b) The water stability of aggregates was significantly ameliorated by the ADNB treatment, which generated a protective shell with a particle-polymer matrix after evaporation of the water in the solution.

(c) Aggregates with an average diameter of $15 \mathrm{~mm}$ exhibited an improved water stability over those with an average diameter of $7.5 \mathrm{~mm}$ when treated with the same concentration of polymer emulsion. This result could be explained by the fact that larger aggregates had smaller specific surface areas, on which there were larger amounts of effective polymeric emulsions than on aggregates with smaller diameters.

(d) Based on the SEM results, two ways for ADNB to stabilize particles were observed: formation of a membrane structure on the surface and chain bonding inside. The latter had a weak bonding effect. The membrane structure that coated the soil particles and/or filled the pores via bonding was believed to play the main role in generating water stability.

(e) The higher the concentration of the polymer emulsion was, the larger the thickness of the polymer membranes and the higher the water stability of the aggregates. However, the most economical and effective concentration for engineering applications was $2 \%$ ADNB.

When ADNB is sprayed on a slope, the protective shell on the soil surface and large aggregates in the subsoil can not only prevent the loss of topsoil but also increase the number of pores of the soil interior, thereby enhancing the permeability of water and air in the soil, which is very important to the growth of plant roots in soil. Furthermore, because the final degradation products $\left(\mathrm{CO}_{2}\right.$ and $\left.\mathrm{H}_{2} \mathrm{O}\right)$ do not pollute the environment, the application of $\mathrm{ADNB}$ can achieve the purpose of the ecological protection of the topsoil of clayey slopes.

Author Contributions: Conceptualization, C.Z. and Z.L.; Data curation, C.Z., S.Z. and Z.L.; Formal analysis, S.Z., W.H., D.L. and Z.L.; Funding acquisition, C.Z. and Z.L.; Investigation, S.Z. and Z.L.; Methodology, C.Z. and Z.L.; Project administration, C.Z. and Z.L.; Resources, C.Z. and Z.L.; Software, S.Z., W.H. and D.L.; Supervision, C.Z. and Z.L.; Validation, C.Z., Z.L. and S.Z.; Visualization, Z.L.; Writing-original draft, C.Z., S.Z. and Z.L.; Writing-review \& editing, C.Z., S.Z. and Z.L.

Funding: This research was supported by the Major Programs Special Funds of Applied Science and Technology Research and Development of Guangdong Province (No. 2015B090925016), the National Key Research and Development Project of China (No. 2017YFC1501201) and the National Key Research and Development Project of China (No. 2017YFC0804605).

Conflicts of Interest: The authors declare no conflict of interest.

\section{References}

1. Petry, T.M.; Little, D.N. Review of Stabilization of Clays and Expansive Soils in Pavements and Lightly Loaded Structures-History, Practice, and Future. J. Mater. Civ. Eng. 2002, 14, 447-460. [CrossRef]

2. Lekha, K.R. Field instrumentation and monitoring of soil erosion in coir geotextile stabilised slopes-A case study. Geotext Geomembr. 2004, 22, 399-413. [CrossRef]

3. Poh, P.S.H.; Broms, B.B. Slope stabilization using old rubber tires and geotextiles. J. Perform. Constr. Fac. 1995, 9, 76-79. [CrossRef]

4. Shao, Q.; Gu, W.; Dai, Q.; Makoto, S.; Liu, Y. Effectiveness of geotextile mulches for slope restoration in semi-arid northern China. Catena 2014, 116, 1-9. [CrossRef] 
5. Smets, T.; Poesen, J.; Fullen, M.A.; Booth, C.A. Effectiveness of palm and simulated geotextiles in reducing run-off and inter-rill erosion on medium and steep slopes. Soil Use Manag. 2007, 23, 306-316. [CrossRef]

6. Basha, E.A.; Hashim, R.; Mahmud, H.B.; Muntohar, A.S. Stabilization of residual soil with rice husk ash and cement. Constr. Build. Mater. 2005, 19, 448-453. [CrossRef]

7. Edil, T.B.; Acosta, H.A.; Benson, C.H. Stabilizing Soft Fine-Grained Soils with Fly Ash. J. Mater. Civ. Eng. 2006, 18, 283-294. [CrossRef]

8. Horpibulsuk, S.; Phetchuay, C.; Chinkulkijniwat, A. Soil Stabilization by Calcium Carbide Residue and Fly Ash. J. Mater. Civ. Eng. 2011, 24, 184-193. [CrossRef]

9. Kaniraj, S.R.; Havanagi, V.G. Compressive strength of cement stabilized fly ash-soil mixtures. Cem. Concr. Res. 1999, 29, 673-677. [CrossRef]

10. Kolias, S.; Kasselouri-Rigopoulou, V.; Karahalios, A. Stabilisation of clayey soils with high calcium fly ash and cement. Cem. Concr. Compos. 2005, 27, 301-313. [CrossRef]

11. Miller, G.A.; Azad, S. Influence of soil type on stabilization with cement kiln dust. Constr. Build. Mater. 2000, 14, 89-97. [CrossRef]

12. Tang, C.; Shi, B.; Gao, W.; Chen, F.; Cai, Y. Strength and mechanical behavior of short polypropylene fiber reinforced and cement stabilized clayey soil. Geotext Geomembr. 2007, 25, 194-202. [CrossRef]

13. Zhu, Z.; Liu, S. Utilization of a new soil stabilizer for silt subgrade. Eng. Geol. 2008, 97, 192-198. [CrossRef]

14. Yue, Z.; Watts, D. Current development of slope eco-engineering principle and application in Europe and America. J. Soil Eros. Soil Water Conserv. 1999, 5, 80-86.

15. Bian, P.; Zhang, J.; Zhang, C.; Huang, H.; Rong, Q.; Wu, H.; Li, X.; Xu, M.; Liu, Y.; Ren, S. Effects of Silk-worm Excrement Biochar Combined with Different Iron-Based Materials on the Speciation of Cadmium and Lead in Soil. Appl. Sci. 2018, 8, 1999. [CrossRef]

16. Chang, I.; Cho, G. Strengthening of Korean residual soil with $\beta-1,3 / 1,6$-glucan biopolymer. Constr. Build. Mater. 2012, 30, 30-35. [CrossRef]

17. Latifi, N.; Rashid, A.S.A.; Siddiqua, S.; Horpibulsuk, S. Micro-structural analysis of strength development in low- and high swelling clays stabilized with magnesium chloride solution-A green soil stabilizer. Appl. Clay Sci. 2015, 118, 195-206. [CrossRef]

18. Liu, J.; Shi, B.; Jiang, H.; Bae, S.; Huang, H. Improvement of water-stability of clay aggregates admixed with aqueous polymer soil stabilizers. Catena 2009, 77, 175-179. [CrossRef]

19. Ma, G.; Ran, F.; Feng, E.; Dong, Z.; Lei, Z. Effectiveness of an Eco-friendly Polymer Composite Sand-Fixing Agent on Sand Fixation. Water Air Soil Pollut. 2015, 226, 221. [CrossRef]

20. Marto, A.; Boss, S.; Makhtar, A.M.; Latifi, N. Strength Characteristic of Brown Kaolin Treated with Liquid Polymer Additives. J. Teknol. 2015, 76, 89-94. [CrossRef]

21. Marto, A.; Latifi, N.; Eisazadeh, A. Effect of Non-Traditional Additives on Engineering and Microstructural Characteristics of Laterite Soil. Arab. J. Sci. Eng. 2014, 39, 6949-6958. [CrossRef]

22. Mousavi, F.; Abdi, E.; Rahimi, H. Effect of polymer stabilizer on swelling potential and CBR of forest road material. Ksce J. Civ. Eng. 2014, 18, 2064-2071. [CrossRef]

23. Naeini, S.A.; Ghorbanalizadeh, M. Effect of wet and dry conditions on strength of silty sand soils stabilized with epoxy resin polymer. J. Appl. Sci. (Faisalabad) 2010, 10, 2839-2846. [CrossRef]

24. Naeini, S.A.; Naderinia, B.; Izadi, E. Unconfined compressive strength of clayey soils stabilized with waterborne polymer. Ksce J. Civ. Eng. 2012, 16, 943-949. [CrossRef]

25. Onyejekwe, S.; Ghataora, G.S. Soil stabilization using proprietary liquid chemical stabilizers: Sulphonated oil and a polymer. B Eng. Geol. Environ. 2015, 74, 651-665. [CrossRef]

26. Shrivastava, A.K.; Jain, D.; Vishwakarma, S. Frictional resistance of drilling fluids as a borehole stabilizers. Int. J. Geo-Eng. 2016, 7, 12. [CrossRef]

27. Zhang, M.; Guo, H.; El-Korchi, T.; Zhang, G.; Tao, M. Experimental feasibility study of geopolymer as the next-generation soil stabilizer. Constr. Build. Mater. 2013, 47, 1468-1478. [CrossRef]

28. Song, Z.; Liu, J.; Bai, Y.; Wei, J.; Li, D.; Wang, Q.; Chen, Z.; Kanungo, D.P.; Qian, W. Laboratory and Field Experiments on the Effect of Vinyl Acetate Polymer-Reinforced Soil. Appl. Sci. 2019, 9, 208. [CrossRef]

29. Escolano, F.; Sánchez, J.; Pacheco-Torres, R.; Cerro-Prada, E. Strategies on Reuse of Clayey Expansive Soils as Embankment Material in Urban Development Areas: A Case Study in New Urbanized Zones. Appl. Sci. 2018, 8, 764. [CrossRef] 
30. Latifi, N.; Vahedifard, F.; Ghazanfari, E.; Safuan, A. Sustainable Usage of Calcium Carbide Residue for Stabilization of Clays. J. Mater. Civ. Eng. 2018, 30, 04018099. [CrossRef]

31. Latifi, N.; Eisazadeh, A.; Marto, A.; Meehan, C.L. Tropical residual soil stabilization: A powder form material for increasing soil strength. Constr. Build. Mater. 2017, 147, 827-836. [CrossRef]

32. Latifi, N.; Horpibulsuk, S.; Meehan, C.L.; Majid, M.Z.A.; Tahir, M.M. Improvement of Problematic Soils with Biopolymer-An Environmentally Friendly Soil Stabilizer. J. Mater. Civ. Eng. 2016, 29, 04016204. [CrossRef]

33. García-Orenes, F.; Guerrero, C.; Mataix-Solera, J.; Navarro-Pedreño, J.; Gómez, I.; Mataix-Beneyto, J. Factors controlling the aggregate stability and bulk density in two different degraded soils amended with biosolids. Soil Tillage Res. 2005, 82, 65-76. [CrossRef]

34. Inyang, H.I.; Bae, S. Polyacrylamide sorption opportunity on interlayer and external pore surfaces of contaminant barrier clays. Chemosphere 2005, 58, 19-31. [CrossRef] [PubMed]

35. Nadler, A.; Perfect, E.; Kay, B.D. Effect of Polyacrylamide Application on the Stability of Dry and Wet Aggregates. Soil Sci. Soc. Am. J. 1996, 60, 555-561. [CrossRef]

36. Salehpour, S.; Jonoobi, M.; Ahmadzadeh, M.; Siracusa, V.; Rafieian, F.; Oksman, K. Biodegradation and ecotoxicological impact of cellulose nanocomposites in municipal solid waste composting. Int. J. Biol. Macromol. 2018, 111, 264-270. [CrossRef]

37. Zhou, Z.; Zeng, J. A Hydrolysis-Resistant Polyester, Hydrolysis-Resistant Waterborne Polyester Dispersion and Its Application. CN104629034 B, 29 September 2017.

(C) 2019 by the authors. Licensee MDPI, Basel, Switzerland. This article is an open access article distributed under the terms and conditions of the Creative Commons Attribution (CC BY) license (http://creativecommons.org/licenses/by/4.0/). 